\title{
Capsule Commentary on True et al., Open Access in the Patient Centered Medical Home: Lessons from the Veterans Health Administration
}

Josephine M. Mancuso, PhD, ANP-BC

Clement J. Zablocki VA Medical Center, Milwaukee, WI, USA.

J Gen Intern Med 28(4):568

DOI: $10.1007 / \mathrm{s} 11606-012-2305-0$

(c) Society of General Internal Medicine 2012

$\mathrm{T}$ he Patient Centered Medical Home (PCMH) is an innovative model to improve primary care by utilizing a team-based, continuous care approach to patient health care. The medical home encompasses comprehensive, patient centered, coordinated, and accessible health care, and demonstrates a commitment to ongoing engagement in activities that promote evidence-based practice to deliver quality and safe patient care. ${ }^{1}$ In April 2010, the Veterans Health Administration (VHA) launched their PCMH initiative, the Patient Aligned Care Team (PACT). ${ }^{2}$

Open access is one aspect of increasing patient-centeredness, creating schedules that accommodate patients' desire for same day and future appointments. True and her colleagues examined the VHA's experience with implementing open access across a six-state region. ${ }^{2}$ Utilizing qualitative methods, they delineated three key characteristics that facilitated or impeded change: leadership engagement, staffing resources, and access to information and knowledge. Progress depended on attitudes or actions of local administrators to restructure clinic schedules of providers and RNs, to accommodate time for same-day/ walk-in patients, telephone clinics, and shared medical appointments. Staffing, in particular personnel to staff PACT teams, was a significant barrier in achieving open access, with some facilities developing alternative strategies based on local resources, i.e. different team configurations.
Finally, obtaining health information (i.e. empanelment data) from the electronic medical record, and the lack of personnel with the skills needed to access centralized data or to generate daily reports, was an obstacle to implementing open access.

Organizational leadership and support is essential to accomplish any large scale system change. The PCMH is emerging as a significant health care reform in the U.S. ${ }^{3}$ and multiple studies indicate that PCMHs reduce medical costs. ${ }^{4}$ However, few studies examine the organizational processes essential to implement PCMHs. This study provides a glimpse of potential barriers and facilitators at the organizational level when establishing the PCMH.

Corresponding Author: Josephine M. Mancuso, $P h D, A N P-B C$; Clement J. Zablocki VA Medical Center, 5000 W National Ave, Milwaukee, WI 53295, USA (e-mail: josephine.mancuso@va.gov).

\section{REFERENCES}

1. Agency for Healthcare Research and Quality. Patient-centered medical home resource center. Available at: http://pcmh.ahrq.gov/portal/server.pt/ community/pcmh_home/1483/PCMH_Defining\%20the\%20PCMH_v2. Accessed November 27, 2012.

2. True G, Butler AE, Lamparska BG, et al. Open access in the patient centered medical home: lessons from the Veterans Health Administration. J Gen Intern Med. 2013; doi:10.1007/s11606-012-2279-y.

3. Strange KC, Nutting PA, Miller WL, et al. Defining and measuring the patient-centered medical home. J Gen Intern Med. 2010;25:601-612.

4. Nielsen M, Langner B, Zema C, Hacker T, Grundy P. Benefits of implementing the primary care patient-centered medical home: A review of cost \& quality results, 2012. Available at: http://www.pcpcc.net/files/ benefits_of_implementing_the_primary_care_pcmh_0.pdf. Accessed November $27,2012$. 